DOI: https://doi.org/10.24867/16AM05Herbut

\title{
PREGLED PRIMENA SAVREMENIH TEHNOLOGIJA U NISKOTEMPERATURSKIM SISTEMIMA DALJINSKOG GREJANJA
}

\section{REVIEW OF APPLICATIONS OF MODERN TECHNOLOGIESIN LOW- TEMPERATURE DISTRICT HEATING SYSTEMS}

\author{
Elena Herbut, Fakultet tehničkih nauka, Novi Sad
}

\begin{abstract}
Oblast- MAŠINSTVO
Kratak sadržaj - U radu su predstavljene nove tehnologije daljinskog grejanja sa nižim temperaturama distribucije. Data je detaljna analiza sistema, primena čistih tehnologija. Pored prednosti sistema, navedeni su $i$ mogući kvarovi i prepreke prilikom implementacije. Dati su primeri primene same tehnologije $i$ postignute ekonomske, ekološke i energetske uštede.
\end{abstract}

Ključne reči: Daljinsko grejanje, niske temperature, grejanje prostora

Abstract - The thesis present a new district heating tehnologies with lower distribution temperatures. A detailed analysis of system and usage of clean tehnologies is given and presented. In addition to the advantages of the system, possible failures and obstacles during implementation are also listed. Examples of the applicatioon of the tehnology itself and the achieved economic and environmental and energy savings are given.

Keywords: District heating, low temperature, space heating

\section{UVOD}

Interpretacijom studije „Niskotemperatursko daljinsko grejanje, Vodič za implementaciju“ i obrađivanjem informacija, dolazi se do potrebnih saznanja koja olakšavaju implementaciju niskotemperaturskih sistema daljinskog grejanja (LTDH). Ovi sistemi obezbeđuju obnovljivu toplotu i toplotu sa niskim temperaturama $\mathrm{u}$ mreži po nižoj ceni u odnosu na sisteme grejanja sa visokim temperaturama.

Cilj primene LTDH predstavlja efikasan način eliminisanja upotrebe fosilnih goriva za grejanje. Zamena fosilnih goriva je od suštinskog značaja za smanjenje globalnog zagrevanja prilikom sagorevanja fosilnih goriva i emisija ugljen-dioksida. Predstavljeni su saveti za postizanje nižih temperatura za grejanje i novih funkcija u postojećim i novim sistemima daljinskog grejanja.

Tokom poslednje decenije, naziv „Daljinsko grejanje četvrte generacije“ (4GDH) korišćen je za opis poboljšanih sistema daljinskog grejanja. Sveobuhvatni cilj ovih sistema je dobijanje potpuno dekarbonizovanih sistema daljinskog grejanja. Takođe, izraz 4GDH primenjuje se na sve nove tehnološke karakteristike i koncepte koji koriste niske temperature, a koji se smatraju najbolje dostupnim od 2020. godine pa nadalje.

\section{NAPOMENA:}

Ovaj rad proistekao je iz master rada čiji mentor je bio dr Aleksandar Anđelković.

\section{2. ČETVRTA GENERACIJA SISTEMA DALJINSKOG GREJANJA}

Zbog rastuće svesti o globalnom zagrevanju pronašao se potencijal $\mathrm{i}$ interes u sistemima daljinskog grejanja kao alat za zamenu fosilnih goriva sa obnovljivim izvorima energije. Time je počelo i razvijanje sistema daljinskog grejanja $\mathrm{i}$ istraživanje $\mathrm{u}$ primeni različitih niskotemperaturskih izvora toplote kao najbolje rešenje za postizanje energetske efikasnosti i smanjenja emisije gasova staklene bašte.

Četvrta generacija sistema daljinskog grejanja predstavlja tehnološki koncept, koji kroz pametne toplotne mreže obezbeđuju razvoj održivih energetskih sistema i podrazumeva integraciju svih raspoloživih izvora toplote $u$ jednu jedinstvenu mrežu (otpadna toplota iz industrije, toplota iz obnovljivih izvora energije, kogeneracija i dr.) za snabdevanje toplotnom energijom za grejanje niskoenergetskih zgrada, sa niskim gubicima i visokom energetskom efikasnošću.

Poslednjih godina građevinska industrija je pronašla način da stvara zgrade sa niskim zahtevima za toplotom. Ova tehnologija se takođe primenjuje na postojećim zgradama. Zbog toga se potrebe za toplotom stalno smanjuju.

Ovom tehnološkom transformacijom, za koju motiv imaju i potrošači i energetske kompanije, teži se ka inteligentnim sistemima daljinske energetike u gradovima.

\subsection{Prepreke i uslovi za niskotemperaturske sisteme}

Tehnologija daljinskog grejanja mora biti redizajnirana kako bi ispunila nove uslove za isporuku i snabdevanje toplotom.

Opšti uslovi i neophodne sposobnosti 4GDH su:

- Snabdevanje LTDH za grejanje prostora i pripremu tople vode,

- Distribuciju toplote sa malim gubicima u mreži;

- Recikliranje toplote iz izvora niske temperature $\mathrm{i}$

- Integrisanje toplotnih mreža u pametan energetski sistem.

Stepen slobode je veći za nove sisteme daljinskog grejanja nego za postojeće. Međutim, mogućnost korišćenja nižih temperatura u ovim sistemima može biti otežana ako se opslužuju stare zgrade sa većim zahtevima za toplotom i temperaturom. Snižavanje zahteva za temperaturom unutar zgrada moguće je uz niske ili umerene troškove. 


\section{PRIMENJENA STUDIJA U KAMPUSU U NEMAČKOJ}

Univerzitetski kampus, izgrađen 1960-ih, podeljen je na četiri glavne lokacije, ukupne korisne površine 310.000 $\mathrm{m}^{2}$, u 164 zgrade. Sve zgrade su nestambene, što dovodi do niskih potreba za toplom vodom. Toplotu i električnu energiju za univerzitet trenutno isporučuju gasna postrojenja za kombinovanu proizvodnju toplote i električne energije (CHP), i rezervni kotlovi na gas koji isporučuju samo toplotnu energiju.

\subsection{Potrebni podaci za praćenje sistema}

Potrošnja toplote se meri preko funkcije zapreminskog protoka i temperature dovoda i povrata grejanja. Protok toplote ka potrošaču iz kruga grejanja određuje se primenom formule prvog zakona za stacionarni protok kroz podstanicu:

$$
\dot{Q}_{i, j}=\dot{V}_{i, j} \cdot \rho_{w} \cdot c_{w} \cdot\left(T_{S, i, j}-T_{R, i, j}\right)
$$

Da bi se identifikovalo gde primeniti koju meru za smanjenje temperature mreže, neophodni su podaci sa primarnih i sekundarnih nadzora grejanja.

Primarne podatke prati 29 brojila toplote za 32 zgrade povezane na daljinsko grejanje (vidi sliku 3.1.). Neke zgrade sadrže zasebne merne elemente u podstanicama za grejanje prostora i pripremu tople vode, dok se u drugim slučajevima, nekoliko krugova grejanja zgrada meri u jednoj mernoj tački. Na sekundarnoj strani, 37 krugova grejanja u 13 različitih zgrada opremljeno je meračima toplote. Nije bilo moguće instalirati brojila toplote u svakuj zgradi i krugu grejanja, stoga su prioritet imale zgrade sa velikom potražnjom za toplotom i velikim povratnim temperaturama. Neke nove zgrade sa niskim temperaturama opremljene su brojilom toplote.

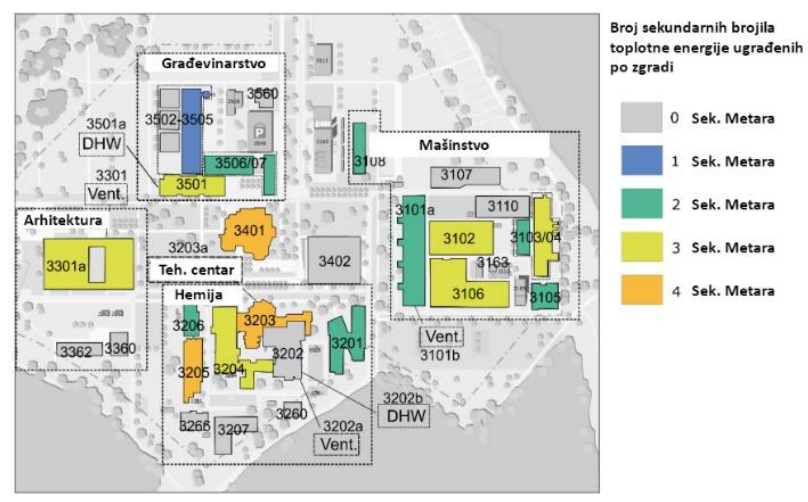

Slika 3.1. Primarna i sekundarna brojila toplote

Analiza performansi sekundarnih krugova grejanja zasnovana je na nedeljnim vremenskim serijama između 18. marta 2020. i 26. marta 2020. Ovaj vremenski period predstavlja prvu sedmicu ograničenja socijalnog distanciranja COVID-19, što je dovelo do toga da je izuzetno mali broj studenata, kao i nastavnika i osoblja, bilo prisutno u zgradama univerziteta. Stoga je potražnja za toplom vodom bila znatno manja nego tokom normalnog rada. Efekat zaključavanja na grejanje prostora je relativno nizak jer zgrade moraju ostati zagrejane i ako je prisutno samo nekoliko ljudi.

\subsection{Identifikacija objekta sa mogućim smanjenjem temperatura}

Da bi se identifikovali najkritičniji objekti sa povišenim povratnim temperaturama, prvo se izračunava potencijal smanjenja povratne temperature za svaku podstanicu u mreži (jednačina 3.2.):

$$
\Delta \bar{T}_{R, j}=\frac{1}{n_{t s}} \sum_{i=1}^{n_{t s}} \frac{\left(T_{R, i, j}-T_{\text {target }}\right) \cdot M_{l, j}}{\sum_{i=1}^{n_{\text {sub }}} M_{i, j}}
$$

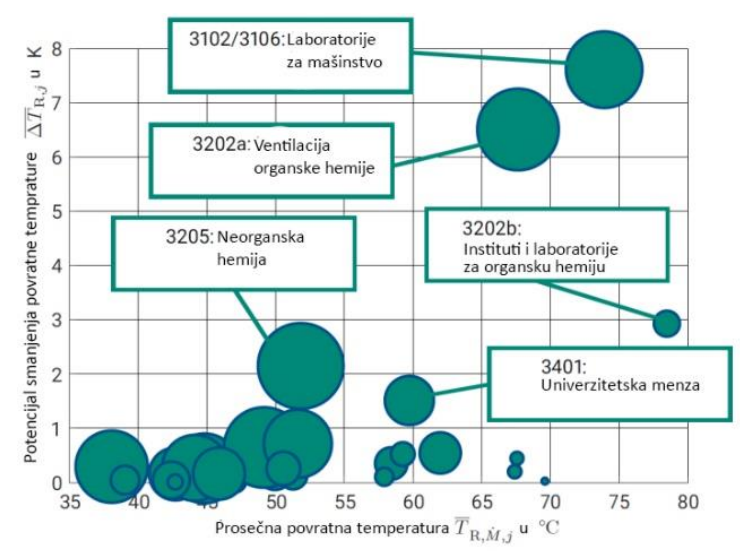

\section{Slika 3.2. Potencijal smanjenja temperature povrata} iznad prosečne temperature povrata

Na slici 3.2. veličina tačaka predstavlja prosečnu godišnju potrošnju toplote za svaku podstanicu. Analiza pokazuje da veliki potencijal za smanjenje temperature povrata nije povezan samo sa podstanicama sa visokim apsolutnim temperaturama povrata, već takođe može biti rezultat veoma velikog masenog protoka pri umerenoj temperaturi povrata, usled velikih potreba za toplotom. Pet najkritičnijih podstanica su od 3102 do 3106, kao i zgradama, 3202, 3205 i 3401. Pet kritičnih podstanica predstavljaju potencijal smanjenja temperature povrata od skoro $21 \mathrm{~K}$. U obzir je uzeta i ventilacija organske hemije, zato što koriste metod rekuperacije toplote, kao dodatan izvor toplote za grejanje.

\subsection{Mere za poboljšanje}

1. Priprema tople vode: Rezervoar za pripremu tople vode u krugu grejanja $3202 b$ treba zameniti električnim grejačem, a način rada rezervoara tople vode u 3401 treba prilagoditi na sledeći način. Ako pravila za higijenu vode to dozvoljavaju, rezervoar se može zagrejati samo tokom radnog vremena, kao što je primenjeno u slučaju rezervoara u krugu grejanja 3501a. Ovo nije idealno rešenje, ali je jednostavan način da se smanji prosečna temperatura povrata iz ovog kruga grejanja bez dodatnih troškova.

2. Obnova zgrade: Sveobuhvatnu obnovu treba izvršiti u zgradi 3205. U ovom slučaju, specifična potrošnja toplote i temperature su visoke iako kontrola krugova grejanja prostora funkcioniše ispravno. Dodatno podno zagrevanje bi bilo opcija za smanjenje zahteva za zagrevanjem prostora. Iako je ova zgrada sagrađena u kampusu (1995.), zahteva rekonstrukciju koja podrazumeva promenu krova zato što prokišnjava. Zgrada 3202, koja takođe pokazuje veoma velike specifične potrebe za toplotom, već se 
renovira. Priprema zgrade za grejanje na niskim temperaturama ključni je aspekt ovog procesa.

3. Smanjenje temperature napajanja daljinskim grejanjem: Mnogi krugovi grejanja ne zahtevaju trenutni visoki nivo napajanja daljinskim grejanjem, već rade na znatno nižim sekundarnim temperaturama napajanja. Oni koji koriste primarnu temperaturu napajanja često pokazuju greške $u$ kontroli.

Nakon otklanjanja grešaka u upravljanju u zgradama 3102/3106, 3105, 3202, 3203, 3205, 3301 i 3401, temperatura napajanja se može smanjivati korak po korak. Takođe, u nekim zgradama upotreba dodatne toplotne pumpe bi bila odlična opcija da se izbegnu izuzetno visoke temperature povrata sa tih podstanica.

\subsection{Energetsko, ekonomsko i ekološko poređenje}

Na slici 3.3. prikazan je uticaj različitih mera na temperaturu povrata u kampusu. Smanjenje temperature su nešto veće u letnjim mesecima nego tokom zime. Ukupni gubici toplote iz cevi daljinskog grejanja, se mogu u proseku smanjiti za $5 \%$.

Treći grafikon omogućava razumevanje uticaja predloženih mera na toplotno snabdevanje kampusa. Prema scenariju, godišnje snabdevanje toplotom smanjeno je za 15,5\%.

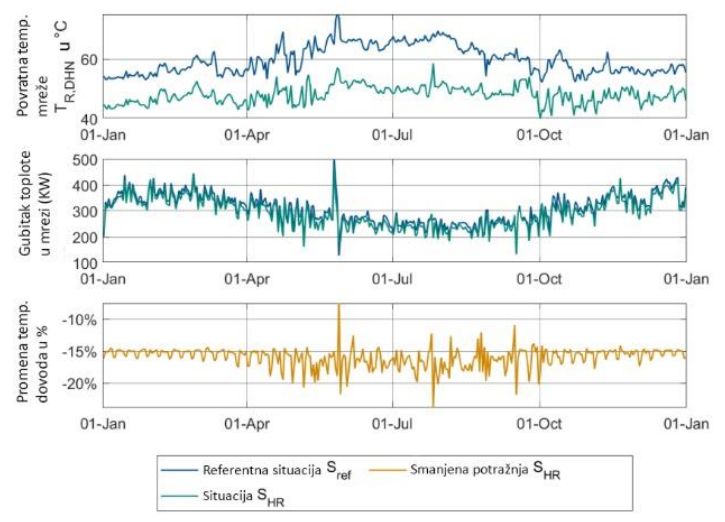

Slika 3.3. Uticaj predloženih mera

Na slici 3.4. prikazan je dijagram na kojem su rezultati za različite vrste energije relevantne za energetski sistem: toplota iz kotlova, toplota i električna energija iz kombinovanih toplana i elektrana (CHP), energija hlađenja iz apsorpcionih hladnjaka i kompresioni rashladnici, električna energija koja se isporučuje iz mreže i električna energija za potrebe proizvodnje, kao što su cirkulacione pumpe.

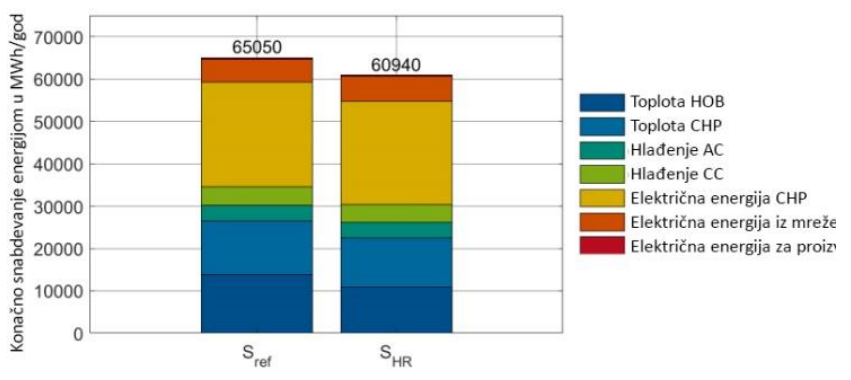

Slika 6.11. Uticaj predloženih mera za smanjenje temperature
Godišnje snabdevanje energijom se smanjuje za oko $6 \%$. To je uglavnom zbog smanjenja potrebe za toplotnom energijom iz kotlova za grejanje za 22\% (3000 MWh). Snabdevanje toplote CHP-om je takođe smanjeno za 9$10 \%$, što je dovelo do povećanja napajanja iz javne mreže za $9 \%$.

Ukupne emisije ugljen-dioksida mogu smanjiti za 4,5\%, dok se emisije koje se odnose na snabdevanje toplotom smanjuju za $19 \%$.

Budući da smanjenje potražnje za toplotnom energijom dovodi do smanjenja proizvodnje električne energije $u$ CHP-u, potražnja za električnom energijom u mreži se povećava, što dovodi do većih udela troškova za snabdevanje električnom energijom.

Maksimalno početno ulaganje $\mathrm{C}_{0}$ može da se izračuna, uzimajući u obzir investicije $A_{\text {inv }}$ i troškove vezane za operacije $A_{o p}$ jednako je smanjenju troškova vezanih za kapacitete, potražnju i emisije. Izračunavanje $\mathrm{C}_{0}$ predstavljeno je jednačinom 3.3.;

$$
C_{o}=\frac{A_{\text {inv }}+A_{o p}}{f_{a} \cdot\left(1+f_{o p} \cdot f_{b}\right)}=1,2 \text { M euro }
$$

Predložene mere su ekonomski izvodljive, sve dok ukupna investicija ne prelazi $1,2 \mathrm{M} €$.

\subsection{Zaključak iz primenjene studije}

Očigledno je da greške u radu unutar infrastrukture zgrada dovode do značajnog povećanja temperature mreže i pokazuje da pojedinačni problemi u nekoliko zgrada mogu imati značajan uticaj na celu mrežu.

Da bi se mogao realizovati prelaz sa fosilnog na obnovljivo daljinsko grejanje, neophodno je prvo primeniti prelaz sa $2 \mathrm{GDH}$ ili $3 \mathrm{GDH}$ na LTDH. Ipak, biće potrebna reorganizacija kako bi LTDH bio ekonomski izvodljiv.

\section{TRANZICIJA NOVOSADSKE TOPLANE}

Novosadska toplana je promenila način grejanja tako što je prešla sa režima grejanja sa prekidom u radu na neprekidni režim. U ovom režimu se razlikuju 2 režima:

- Komforni režim - 16h (4-20h) i

- Noćni režim - 8h (20-4h).

Time se smanjio dodatni potreban kapacitet za jutarnji pik $\mathrm{u}$ odnosu na period kada je sistem bio u režimu sa prekidom $u$ radu.

Postepenim podizanjem temperature na prelazu između 2 režima, sa manjom temperaturskom razlikom u odnosu na prekidni režim, smanjeni su udari na mrežu u vidu nagle dilatacije cevovoda $\mathrm{i}$ instalacija. Takođe, specifični utrošak energije je manji jer su i temperature i dovoda i povrata niže uz bolji subjektivni oseća kod potrošača.

Novosadska toplana je postigla velike pomake na polju upravljanja i nadzora koje su na nivou 4GDH implementacijom softverske platforme ArchestrA System Platform, koja pruža integraciju: 
- Sistema za nadzor i upravljanje toplotnih izvora,

- Sistema za nadzor i upravljanje toplotnih podstanica;

- Sistema za nadzor i upravljanje toplotnih izvora;

- Softverskih alata za tehničko-ekonomsku optimizaciju sistema daljinskog grejanja;

- Softverskih alata za upravljanje imovinom i održavanjem;

- Softverskih alata za analizu podataka i energetski menadžment $\mathrm{i}$

- Primenu drugih manjih podsistema i platforma.

Takođe, izvršena je integracija SCADA sistema za nadzora i upravljanja toplotnim izvorima SDG.

Lokaliteti na kojima treba izvršiti proširenje mreže daljinskog grejanja i koji su dislocirani od postojeće toplifikacione infrastrukture, predstavljaju idealna područja za implementaciju najmodernijih koncepta 4G i 5G SDGiH.

Mišeluk je idealan kandidat razvoja nove mreže koja bi se projektovala za 4G SDGiH. Ovaj lokalitet bi Novosadskoj toplani poslužio i kao pilot projekat pomoću koga bi se ispitale stvarne performanse integracije i implementacije više izvora energije $u$ inteligentan i niskougljenični SDGiH. Stečena iskustva se dalje mogu primeniti na ceo novosadski toplifikacioni sistem.

Novosadska toplana ima veoma dobar potencijal za postizanje pametnog i zelenog grada $\mathrm{s}$ obzirom na postojeći nivo automatizacije i umreženosti samog SDG. $\mathrm{Na}$ nivou grada je potrebno implementirati mnogo više „pametnih“ rešenja, kako bi i grad dostigao kapacitete koje imaju pametni gradovi.

\section{ZAKLJUČAK}

Pored utvrđenih mogućnosti i prednosti primene LTDH, predstavljene su i prepreke prilikom implementacije. U poređenju sa današnjim tehnologijama i distribucije toplote, niske temperature zahtevaju neke izmene kako postojećih tako i novih instalacija $u$ zgradama, podstanicama i distributivnim mrežama. Što se tiče postojećih instalacija, samo manji deo mora biti uklonjen ili zamenjen. Definisanjem novih standarda i adaptacija istih, pružiće mogućnost projektovanja novih sistema daljinskog grejanja za implementaciju u novo izgrađene objekte.

Ekonomske koristi od nižih temperatura distribucije toplote biće približno pet puta veće kada se koriste obnovljivi izvori energije i reciklirana toplota u poređenju sa tradicionalnom upotrebom fosilnog goriva.

Primena ovakvih tehnologija i vršenje istraživanja nad njima, doprinosi unapređenju energetskog sistema $\mathrm{i}$ proširivanju saznanja o daljim mogućnostima i predstavlja veliki potencijal za očuvanje životne sredine, nasuprot tome što jos nije ekonomski isplativa prema primeru za Nemački univerzitet. Primer Novosadske toplane i njene tranzicije ka primeni niskotemperaturskih sistema daljinskog grejanja, predstavlja dobar način ka postizanju zelene tehnologije bez velikih investicija i rekonstrukcije postojećeg sistema.

\section{LITERATURA}

[1] „Low-Temperature District Heating Implementation Guidebook" Edited by Kristina Lygnerud and Sven Werner, Halmstad University 2021

[2] Specijalistički rad „Proizvodnja, prenos i distribucija toplotne energije, daljinskog sistema grejanja“, autor: Miroslav Kićanović, Novi Sad

[3] Srbija i klimatske promene - Okvirna Konvencija UN o promeni klime

[4] Srbija i klimatske promene - Kjoto protokol

[5] Balkan green energy news - Datum pristupa: 08.09.2021. Preuzeto sa linka:

[6] Skripta „Savremene energetske tehnologije”, autor: Željko Vlaović, 2019. godina. FTN Novi Sad

[7] „International review of district heating and cooling“, Sven Warner, april 2017. godine. - „Međunarodni pregled daljinskog grejanja i hlađenja“

[8] "Assessing the techno-economic impact of lowtemperature subnets in conventional district heating networks", Jose Fiacro Castro Flores, Justin N.W. Chiu, Viktoria Martin, Bruno Lacarrière, jun 2017. godine "Procena tehno-ekonomskog uticaja niskotemperaturnih mreža u konvencionalnim mrežama daljinskog grejanja" -

[9] „Obnovljivi izvori energije“, autori: Gvozdenac Dušan, Nakomčić-Smaragdakis Branka, GvozdenacUrošević Branka, 2011. godine. FTN Novi Sad

[10] „Performance of Flat-Plate and Compound Parabolic Concentrating Solar Collectors in Underfloor Heating Systems", Sarvenaz Sobhansarbandi, Ugur Atikol, jun 2015. godine. - „Performanse ravnih ploča i složenih paraboličkih koncentrirajućih solarnih kolektora u sistemima podnog grejanja“.

[11] „Bottlenecks in district heating systems and how to address them", Lisa Brangea, Jessica Englundb, Kerstin Sernheda, Marcus Therna and Patrick Lauenburg, 2017. godine. - „Uska grla u sistemima daljinskog grejanja $\mathrm{i}$ kako ih rešiti".

[12] Strategija razvoja JKP „Novosadska toplana“ do 2030. godine, Novi Sad, FTN 2021.

[13] Averfalk, H. et al., (2017). „Transformation Roadmap from High to Low Temperature District Heating Systems": Annex XI final report. International Energy Agency - Averfalk, H. (2017) - „Mapa puta transformacije iz sistema daljinskog grejanja na niskim temperaturama“: Aneks KSI završni izveštaj. Međunarodna agencija za energiju

[14] Akcioni plan zeleni grad Novi Sad

\section{Kratka biografija:}

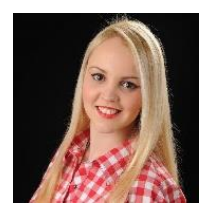

Elena Herbut rođena je u Novom Sadu 1997. god. Osnovne studije na Fakultetu tehničkih nauka iz oblasti Mašinstvo Energetika i procesna tehnika završila je 2020. god. Trenutno student master studija na smeru Termoenergetika. 